\title{
Assessment of Basic Factors of Current Classes for Children with Autism Spectrum Disorders in Vietnam
}

\author{
Nguyen Nu Tam An ${ }^{*}$ \\ Faculty of Special Education, Hanoi National University of Education, Hanoi, Vietnam \\ *Corresponding author: nguyennutaman@gmail.com
}

Received November 26, 2018; Revised January 07, 2019; Accepted January 09, 2019

\begin{abstract}
The models of classes for children with autism spectrum disorders have been developed in Vietnam for almost 20 years with a recent rapid growth in quantity. However, there has yet been a lack of specific orientations and regulations on the basic factors of classes suitable for children with autism spectrum disorders; therefore, those classes have been directed rather freely with numerous issues to discuss. In this research, we have surveyed 71 individuals including teachers and personnel making direct interventions for children with autism spectrum disorders. The survey tools included 52 items in respect of the four main factors: classroom material environment, organization of daily intervention activities, instructions for children's task accomplishment, and in-class communications. The basic factors of classes for children with ASD in Vietnam have been initially established. Apart from the factor of communications with fair progress made, other factors including material environment, organization of daily activities and instructions for task accomplishments are still undergoing multiple restraints. Based on the survey results, this research suggests fundamental strategies to enhance the factors of current classes for children with autism spectrum disorders in Vietnam.
\end{abstract}

Keywords: autism spectrum disorders, models of class, basic factors, classroom material environment, organization of daily intervention activities, instructions for children's task accomplishment, and in-class communications

Cite This Article: Nguyen Nu Tam An, "Assessment of Basic Factors of Current Classes for Children with Autism Spectrum Disorders in Vietnam.” American Journal of Educational Research, vol. 7, no. 1 (2019): 19-23. doi: 10.12691/education-7-1-4.

\section{Introduction}

Children with autism spectrum disorders (ASD) encounter with a lot of difficulties in participating in regular classes. Major difficulties include: troubles with attention and perception of common instructions; inability in identifying personal positions and missions; inability to start, finish, move and continue activities; difficulty in developing interest in cooperative activities; inability in carrying out tasks without sufficient visual aids in educational materials and so on. Because of these issues, the participation of children with ASD is often low; many of them with poor independence in undertaking academic tasks require strong support from teachers; others may even make hazardous behaviors without willingness to participate in lessons and so on [1-4].

The models of classes for children with ASD have been developed differently depending on particular conditions and intervention method orientation. TEACCH-based classes are often well structured; while ABA-oriented classes focus more on individual instructions... [1] Regardless of applied models, classes for children with ASD are designed in respect of basic factors including classroom material environment, organization of daily intervention activities, instructions for children's task accomplishment, and in-class communications... [5,6,7,8]. Gary Mesibov \& Marie Howley (2003) explain way to how structured teaching can enable children with ASD to access the curriculum in a meaningful way and offer many practical strategies to facilitate this process [6].

In Vietnam, classes for children with autism spectrum disorders were initially established and reported in the research "Initial implementation of inclusive education for autistic children in Hanoi" by Nguyen Thi Hoang Yen. Those were classes for children with ASD located in inclusive kindergartens in 2003 [9]. Following reports were undertaken by Do Thuy Lan on the intervention model at Sao Mai Early Intervention Centre - Hanoi, one of the first centers of early interventions for children with ASD in Vietnam [10]; and by Nguyen Thi Hong Thuy (2013) on the model of early interventions at National Children's Hospital... [11]. However, in these models there have not yet been clarifications of basic factors of classes for children with ASD but mostly individual approaches.

Most recently, in her research, Nguyen Nu Tam An (2015) demonstrated the method of applying a particular approach in developing a class model for children with ASD. The paper analyzes the way applying TEACCH method is used in design lesson for children with autism spectrum disorders (ASDs) in view of utilizing the 
advantages of the method with the aim of increasing the degree of independence. The initial evaluation of 32 children with ASDs showed the level of independence and achievement of the children's learning tasks in the class. On the basis of the results of the paper that guided the expansion of the TEACCH model in the education and therapy for children with ASDs

There has yet been a lack of specific orientations and regulations on the basic factors of classes suitable for children with autism spectrum disorders; therefore, those classes have been directed rather freely with numerous issues to discuss. The assessment of basic factors of classes for children with ASD in the current intervention conditions in Vietnam is necessary for a methodical and efficient orientation of intervention models, avoiding the mushrooming of spontaneous, poorly-effective intervention models with difficulties in monitoring and management.

\section{Content}

\subsection{Current Conditions of Basic Factors of Classes for Children with Autism Spectrum Disorders}

\subsubsection{Survey Process Overview}

About survey objects: 71 surveyed teachers and staff have worked in the area of interventions for children with ASD for 73 months on average (SD = 13.1); a majority (90.1\%) of them are female; they are from various cities and provinces including Hanoi, Hai Duong, Thai Binh, Bac Ninh, Vinh Phuc, etc.; $45.1 \%$ of them graduated with degrees in Special Education; 95.8\% of them were professionally trained in the area of intervention approaches for children with disabilities in general and with ASD in particular.

About survey tools: The survey questionnaire used in the research comprises of 52 items categorized into 04 basic factors of a class including: classroom material environment (21 criteria), organization of daily intervention activities (19 criteria), instructions for children's task accomplishment (6 criteria), and in-class communications (6 criteria). This questionnaire has been developed from Divison TEACCH's toolkit.

The appropriacy of each criterion has been calculated using Cronbach's Alpha function. Cronbach's Alpha at 0.7 is considered to be the lowest threshold to accept the internal reliability of the assessment.

Table 1. Internal reliabilities of the categories in the assessment of classes for children with ASD

\begin{tabular}{|l|c|c|}
\hline Category & $\begin{array}{c}\text { Number of } \\
\text { criteria }\end{array}$ & $\begin{array}{c}\text { Internal } \\
\text { Reliability }\end{array}$ \\
\hline 1. Classroom material environment & 21 & 0.751 \\
\hline $\begin{array}{l}\text { 2. Organization of daily intervention } \\
\text { activities }\end{array}$ & 19 & 0.800 \\
\hline $\begin{array}{l}\text { 3. Instructions for children's task } \\
\text { accomplishment }\end{array}$ & 6 & 0.745 \\
\hline 4. In-class communications & 6 & 0.820 \\
\hline Total & $\mathbf{5 2}$ & $\mathbf{0 . 8 9 7}$ \\
\hline
\end{tabular}

Table 1 shows that the internal reliability of each category is above 0.7 and that of the total assessment reaches 0.897 . Therefore, with regard to structural and internal reliabilities, the 52 criteria have met the necessary appropriacies, and thus can be used to assess the classes for children with ASD.

\subsubsection{Analysis of survey results}

2.1.2.1. Percentage of fulfilment of basic factors in classes for children with ASD

Table 2. Percentage of fulfilment of basic factors in classes for children with ASD (n =71)

\begin{tabular}{|c|l|c|c|c|}
\hline No. & Category & Average & Rate & Rank \\
\hline 1 & $\begin{array}{l}\text { Classroom material environment } \\
\text { (21 criteria) }\end{array}$ & 40.6 & 57.2 & 2 \\
\hline 2 & $\begin{array}{l}\text { Organization of daily intervention } \\
\text { activities (19 criteria) }\end{array}$ & 33.2 & 46.7 & 3 \\
\hline 3 & $\begin{array}{l}\text { instructions for children's task } \\
\text { accomplishment (6 criteria) }\end{array}$ & 33.2 & 46.7 & 3 \\
\hline 4 & $\begin{array}{l}\text { In-class communications (6 } \\
\text { criteria) }\end{array}$ & 48 & 67.6 & 1 \\
\hline 5 & Total (52 criteria) & $\mathbf{3 8 . 7}$ & $\mathbf{5 4 . 5}$ & \\
\hline
\end{tabular}

The survey results show that the fulfilment percentage of basis factors in classes for children with ASD is 54.5\% (Table 2). That of the criteria of in-class communications is the highest $(67.6 \%)$ and that of organization of daily intervention activities and of instructions for children's task accomplishment are the lowest (46.7\%). In the next parts of this paper, each category of criteria in current classes for children with ASD will be assessed more specifically.

\subsubsection{Current conditions of classroom material} environment for children with ASD

The fulfilment rates of basic factors in terms of material environment in classrooms for children with ASD vary greatly from $22.5 \%$ to $94.4 \%$ (Table 2 ).

In total there are 6 out 21 criteria with high fulfilment percentage (above $70 \%$ ), including: availability of rooms for children's personal belongings (94.4\%), the controllability of temperature in classrooms (91.5\%), sufficient lighting in classrooms (90.1\%), furniture arrangement for children to move easily to different areas during school time (80.3\%), teachers' conditions to observe important areas in classrooms (74.6\%), children's study areas to be designed with minimized distraction from the environment (73.2\%).

In total there are 7 out of 21 criteria with average fulfilment percentage (from 50\%), including: Clear separation between individual work areas and group work areas (69.0\%), central and easily accessible locations of school supplies in study areas for children (67.6\%), neat organization of objects (66.2\%), desks locations to encourage interactions among children during school time (64.8\%), use of other furniture (dividers, cupboards, etc.) in diminishing distraction for children with difficulty in paying attention to study (53.5\%), children-friendly sizes of furniture in classrooms (53.5\%), different emplacements between objects that children are allowed and not allowed to use (52.1\%).

Accounted for the largest portion, 8 out of 21 criteria with low fulfilment percentage (below 50\%) include: controllability of level of noise (49.3\%), clear transitional areas among different study areas (for children to move in between study areas without disturbing others) (40.8\%), 
objects causing distraction for children while moving in between study areas (39.4\%), furniture and other objects functioning as separators in the classrooms (35.2\%), availability of free-play areas (for relaxation or entertainment) where no instruction is needed (35.2\%), clear labels for all areas for children to determine destinations (31\%), clear labels for areas of free time for children to recognize (25.4\%), closeness between individual work areas and common teaching areas for teachers to manage both of them (22.5\%).

The above results show that basic factors of a normal classrooms have higher fulfilment rates than those of typical classrooms for children with ASD. Children with ASD need private spaces for individual demands (self-study, free play, relaxation, entertainment) to avoid overload of group activities; yet such factors have not been thoroughly acknowledged. Besides, children need a material environment with a clear and easily recognizable structure; however, in reality these criteria have been undervalued. Most educators still design classrooms with the standards for normal classes.

\subsubsection{Current conditions of organizing daily activities at school}

There are only 2 out of 19 criteria with high fulfilment rate (above $70 \%$ ), including: children's participation with others or with teachers $(77.5 \%)$, provision of immediate preferred activities following less favored activities for interventions for troubled behaviors (76.1\%).

There are only 7 out of 19 criteria with average fulfilment rate (from 50\%), including: visually illustrated timetables suitable to children's level of perception and development (69\%); children's awareness of starting and ending time of tasks (63.4\%); good balance among individual instruction time, individual work time, group work time, and time for suitable entertainment according to children's capabilities (59.2\%), fixed and predictable timetables (56.3\%); shortened study hours for stress reduction and external activities (52.1\%); availability of relaxation time for children (52.1\%); children's acknowledgement of destination to go and action to take during the activities (52.1\%) (Table 4).

There are as many as 10 out of 19 criteria with low fulfilment rate (below 50\%), including: children's awareness of destination to go and action to take during transitional intervals (39.4\%), alarming clocks helping children manage their own time during school hours or transitional intervals (39.4\%), transitional intervals scheduled to support interventions for troubled behaviors (36.6\%), provision of habit-based structured activities to minimize self-stimulatory behaviors (35.2\%), clearly presented and fixed visually illustrated timetables for children to acknowledge all activities of the day (33.8\%), the use of timetable with adjustments to help children learn of changes (33.8\%), clear provision of time in timetables for children to be aware of when self-stimulatory behaviors are "acceptable" or "unacceptable" (32.4\%), provision of instruction for children's time management of their own activities to an extent (31\%), schedules of external or communal activities for children to generalize the skills learnt at school (25.4\%), developed consolidations visually marked on children's timetables (23.9\%).

In this category of criteria, it is shown that daily activities have fulfilled basic requirements of classes for children with ASD including children's participation and motivation in activities. Necessary factors in organizing classes for children with ASD such as transition, independence, generalization and so on have low fulfilment rates. In reality, other than individual intervention hours, most in-class activities for children with ASD are similar to that of a normal class and do not meet the learning characteristics of children with ASD.

Table 3. Current conditions of classroom material environment for children with ASD

\begin{tabular}{|c|c|c|}
\hline Criteria & Qty & Pct (\%) \\
\hline 1. There are lockers for children's personal belongings. & 67 & 94.4 \\
\hline 2. Children's study areas are designed to diminish distraction from factors of the environment. & 52 & 73.2 \\
\hline 3. Arrangement of furniture makes it easier for children to move to different areas during school time. & 57 & 80.3 \\
\hline 4. Desks are located in positions that encourage interactions among children during school time. & 46 & 64.8 \\
\hline 5. Other furniture (dividers, cupboards, etc.) are used to diminish distraction for children with difficulties in paying attention to study. & 38 & 53.5 \\
\hline 6. Sizes of furniture are suitable to children. & 38 & 53.5 \\
\hline 7. Apart from furniture, other items function in dividing classrooms into separate areas (such as floor mats, floor separators, etc.) & 25 & 35.2 \\
\hline 8. Individual work areas are clearly separated from group work areas. & 49 & 69.0 \\
\hline 9. Teachers can observe all corners or key corners of the classroom. & 53 & 74.6 \\
\hline 10. Individual work areas and common teaching areas are close enough for teachers to manage both areas simultaneously. & 16 & 22.5 \\
\hline $\begin{array}{l}\text { 11. Transitional areas in between different study areas are clear (children moving among study areas without disturbing other } \\
\text { children). }\end{array}$ & 29 & 40.8 \\
\hline 12. Children are not distracted by objects (that they are interested in or fond of) while moving in between study areas. & 28 & 39.4 \\
\hline 13. There are not excessively plenty of objects in the study areas and the objects are neatly organized. & 47 & 66.2 \\
\hline 14. School supplies are centrally located in study areas and easily accessible for children. & 48 & 67.6 \\
\hline 15. Items not for children's use are placed in different positions than those that children are allowed to use. & 37 & 52.1 \\
\hline 16. There are free-play areas (to relax or entertain) where no instruction is needed (where there are no dangerous items or teachers' items). & 25 & 35.2 \\
\hline 17. Areas for free-play time are clearly labelled for children to recognize. & 18 & 25.4 \\
\hline $\begin{array}{l}\text { 18. All areas in the classroom are labelled with symbols for children to identify the destination (for instance a teacher can tell } \\
\text { them to "go to the place with a blue signage"). }\end{array}$ & 22 & 31 \\
\hline 19. There is sufficient lighting in the classroom. & 64 & 90.1 \\
\hline 20. Temperature in the classroom can be adjusted easily. & 65 & 91.5 \\
\hline 21. Level of noise can be controlled. & 35 & 49.3 \\
\hline Average & 40.6 & 57.2 \\
\hline
\end{tabular}


Table 4. Current conditions of organizing daily activities in classes for children with ASD

\begin{tabular}{|c|c|c|}
\hline Criteria & Qty & Pct (\%) \\
\hline 1. Visually illustrated timetables are clearly presented and fixed for children to acknowledge all activities of the day. & 24 & 33.8 \\
\hline 2. Timetables are fixed and predictable. & 40 & 56.3 \\
\hline 3. Study hours are shortened for stress reduction and external activities. & 37 & 52.1 \\
\hline 4. There are breaks in between study hours. & 37 & 52.1 \\
\hline 5. Preferred activities are provided right after less favored activities for intervention with troubled behaviors. & 54 & 76.1 \\
\hline $\begin{array}{l}\text { 6. There is good balance among individual instruction time, individual work time, group work time, and time for suitable } \\
\text { entertainment according to children's capabilities. }\end{array}$ & 42 & 59.2 \\
\hline 7. Children are aware of destination to go and activity to do during transitional intervals. & 28 & 39.4 \\
\hline 8. Transitional intervals are scheduled to support the intervention with troubled behaviors. & 26 & 36.6 \\
\hline 9. Children are aware of destination to go and action to take during activities. & 37 & 52.1 \\
\hline 10. Children are aware of when to start and end a task. & 45 & 63.4 \\
\hline 11. Timetables provide habit-based structured activities to minimize self-stimulatory behaviors. & 25 & 35.2 \\
\hline 12. Timetables inform children when self-stimulatory behaviors are "acceptable" or "unacceptable". & 23 & 32.4 \\
\hline 13. Children can participate in activities with other children or with teachers. & 55 & 77.5 \\
\hline 14. Some consolidations are developed and visually marked on children's timetables. & 17 & 23.9 \\
\hline 15. Alarming clocks help children manage their own time during school time or transitional time. & 28 & 39.4 \\
\hline $\begin{array}{l}\text { 16. Daily timetables are illustrated with pictures (using objects, pictures, words, or combination of them). Timetables are } \\
\text { suitable to children's levels of perception and development. }\end{array}$ & 49 & 69 \\
\hline 17. Children can manage their time of activities according to the timetables to an extent. & 22 & 31 \\
\hline 18. Timetables are adjusted with minor changes to help children learn about changes. & 24 & 33.8 \\
\hline 19. External or communal activities are scheduled in the timetables to help children generalize the skills learnt at school. & 18 & 25.4 \\
\hline Average & 33.2 & 46.7 \\
\hline
\end{tabular}

2.1.2.4. Current conditions of instruction for children to carry out educational tasks

Table 5. Current conditions of instruction to carry out tasks in classes for children with ASD

\begin{tabular}{|l|c|c|}
\hline Criteria & Qty & Pct \% \\
\hline $\begin{array}{l}\text { 1. Consolidation methods are diversified and classified } \\
\text { to avoid children's apathy. }\end{array}$ & 34 & 47.9 \\
\hline $\begin{array}{l}\text { 2. Extra activities are provided during individual work } \\
\text { hours apart from those that children perform } \\
\text { competently. }\end{array}$ & 20 & 28.2 \\
\hline $\begin{array}{l}\text { 3. Tasks are clearly structured with probably either } \\
\text { simplified or complicated parts using additional } \\
\text { objects. }\end{array}$ & 37 & 52.1 \\
\hline $\begin{array}{l}\text { 4. Preferred tasks are introduced initially to help } \\
\text { comfort children to start the class. }\end{array}$ & 55 & 77.5 \\
\hline $\begin{array}{l}\text { 5. Tasks for independent work are often easier than } \\
\text { tasks that are being taught concurrently. }\end{array}$ & 37 & 52.1 \\
\hline $\begin{array}{l}\text { 6. Symbolization of "What's next?" contains more } \\
\text { motivation to children. }\end{array}$ & 16 & 22.5 \\
\hline Average & 33.2 & $\mathbf{4 6 . 7}$ \\
\hline
\end{tabular}

There is only 1 out of 6 criteria with high fulfilment rate (above $70 \%$ ), which is the initial introduction of preferred tasks for children's comfort to begin the class (77.5\%) (Table 5).

There are 2 out of 6 criteria with average fulfilment rates (from 50\%), including the simplification and shortening of tasks (52.1\%), and easier tasks for independent work than those concurrently instructed by teachers (52.1\%).

There are 3 out of 6 criteria with low fulfilment rates (below 50\%), including: diversity of consolidation activities and types (47.9\%), extra tasks provided to children other than competently performed ones during independent work time (28.2\%), and more motivation in symbolization of "What's next?" (22.5\%).

Children with ASD often have limited organization and motivation in carrying out tasks, therefore these issues are focal points in requirements for instructions to children. In reality these requirements have not yet been well fulfilled. During giving instructions, teachers have not focused on children's independence in carrying out tasks; their problem-solving ability and generalization ability have not been properly addressed.

\subsubsection{Current conditions of in-class communications with children}

There are 4 out of 6 criteria with high fulfilment rates (above 70\%), including: children's demands expression in suitable means of communication (80.3\%), teachers giving clear and consistent communications to children (80.3\%), means of communication other than verbal means to help children aware of activity structures in the class (77.5\%), support for communication skills to enhance children's participation in the class (70.4\%) (Table 6).

There is 1 out of 6 criteria with average fulfilment rate (from 50\%), which is instructions given to children to express their assents or dissents to avoid explosive behaviors (53.5\%).

There is 1 out of 6 criteria with low fulfilment rate (below 50\%), which is accessibility of visual communication tools in all in-class activities (43.7\%).

Table 6. Current conditions of communications in classes for children with ASD

\begin{tabular}{|l|c|c|}
\hline Criteria & Qty & Pct \% \\
\hline $\begin{array}{l}\text { 1. Children can express their demands in suitable } \\
\text { means of communication. }\end{array}$ & 57 & 80.3 \\
\hline $\begin{array}{l}\text { 2. Children are given instructions to express their } \\
\text { assents or dissents to avoid explosive behaviors. }\end{array}$ & 38 & 53.5 \\
\hline $\begin{array}{l}\text { 3. Teachers' communications to children are clear } \\
\text { and consistent. }\end{array}$ & 57 & 80.3 \\
\hline $\begin{array}{l}\text { 4. Visual communication tools are easily accessible } \\
\text { to children for all in-class activities. }\end{array}$ & 31 & 43.7 \\
\hline $\begin{array}{l}\text { 5. Apart from verbal communication means, others } \\
\text { help children aware of activity structures in the class. }\end{array}$ & 55 & 77.5 \\
\hline $\begin{array}{l}\text { 6. Communication skills are supported to enhance } \\
\text { children's participation in the class. }\end{array}$ & 50 & 70.4 \\
\hline Average & $\mathbf{4 8}$ & $\mathbf{6 7 . 6}$ \\
\hline
\end{tabular}


Communication is currently the best category in classes for children with ASD. This is the factor that teachers' proactivity plays an important role, whereas other factors are determined in accordance with the intervention orientation of the school/center and the teachers have limited control even at will. For instance, the school may arrange timetables for all classes and teachers will have to follow them. Or the classroom material environment is already designed for all classes and teachers have no rights to renovate the classrooms under their responsibility upon their own purposes. Without regulation or guidelines specifically for classes for children with ASD, most schools/centers will simply follow the common standard of kindergartens or primary schools.

The four basic factors of the classes for children with ASD have closely mutual bonds. Apart from the factor of in-class communications which depends heavily on the teachers' skills, the other factors are influential to one another. For example, the material environment is the ground for the fulfilment of the two factors of organization of daily activities and instructions for task accomplishment. Therefore, in order to improve the conditions of classes for children with ASD, these factors have to be simultaneously improved.

\subsection{Recommendations of Fundamental Strategies to Enhance Basic Factors of Classes for Children with Autism Spectrum Disorders in Vietnam}

Based on the survey results, this research suggests fundamental strategies to enhance the factors of current classes for children with autism spectrum disorders in Vietnam.

First, documents/guidelines on the standards and class organization should be established for children with ASD. This is the most fundamental foundation for schools/centers to develop their own models. In order to establish these standards, we should refer to those of other countries with extensive experience of interventions for children with ASD and adapt them into actual conditions in Vietnam. These standards should as well be legislated if possible, to ensure effective management and monitoring of class models for children with ASD that have been spontaneously developed recently.

Second, there should be professional trainings for direct managers of schools/centers and managers of the network of schools/centers on the standards as well as enforcement of those standards of classes for children with ASD.

Third, there should be professional trainings for teachers, staff, and technicians who are directly involved with interventions for children with ASD in accordance with these standards. They are the core teams to execute the standards into reality in education for children with ASD.

Forth, basic factors of classes for children with ASD should be expanded step-by-step: From individual study area (in private classrooms) - less restricted study area (back-of-classroom area) - group table (for 4-6 students); From activities of a single class (45 minutes) - activities of a school day (multiple classes) - daily activities (including all activities at school and all activities at school and home); From partial independence (in several steps) - entire independence in a class (in all steps) entire independence of a day.

\section{Conclusion}

The basic factors of classes for children with ASD in Vietnam have been initially established. Apart from the factor of communications with fair progress made, other factors including material environment, organization of daily activities and instructions for task accomplishments are still undergoing multiple restraints. These basic factors can be developed into groups of standards by undertaking applied researches on standards of developed countries with studies on actual conditions in Vietnam. Besides, pilot models may be developed before being put into application and nationwide implementation.

\section{Acknowledgements}

This paper is supported by Vietnam Ministry of Education and Training through the project Applied Research of Therapies in Education for Children with Autism Spectrum Disorder (Code: M2017 - HNUE 40).

\section{References}

[1] Bryna Siegel. (2003). Helping children with Autism learn, Oxford university press

[2] Nguyen Nu Tam An. (2013). Teaching Methods of Reading Comprehension for Children with ASD at Early Primary School, Doctoral Thesis. Hanoi National University of Education.

[3] Nguyen Nu Tam An. (2015). Study on Autistic Children's Readiness for Inclusive Education at Kindergarten. Science Journal, Hanoi National University of Education, No. 60 (8C), 147-152.

[4] Nguyen Nu Tam An. (2017). Application of TEACCH in Designing Education for Children with ASD. Conference Proceedings at National Science Conference "Psychological Educational Applications in ASD Interventions", 394-402, The Gioi Publishers.

[5] Mesibov, G. B., Schopler, \& Hearsey, K. A. (1994). Structured teaching. In E. Schopler \& G. B. Mesibov (Eds.), Behavioral Issues in Autism (pp. 195-207). New York: Plenum Press.

[6] Gary Mesibov \& Marie Howley (2003). Accessing the Curriculum for pupil with utistic spectum Disorder. David Fulton Publishers.

[7] Siaperas, P., \& Beadle-Brown, J. (2006). A case study of the use of a structured teaching approach in adults with autism in a residential home in Greece. Autism, 10, 330-343.

[8] Spriggs, A. D., Gast, D. L., \& Ayres, K. M. (2007). Using picture activity schedule books to increase on-schedule and on-task behaviors. Education and Training in Developmental Disabilities, 42, 209-223.

[9] Nguyen Thi Hoang Yen (2007). Initial implementation of inclusive education for autistic children in Hanoi. Conference Proceedings at First National Science Conference.

[10] Do Thuy Lan (2007). The early intervention model for children with ASD at Sao Mai Early Intervention Centre - Hanoi. Conference Proceedings at First National Science Conference.

[11] Nguyen Thi Hong Thuy, Nguyen Mai Huong, Thanh Ngoc Minh (2013). Results of experimenting the model of early intervention for children with autism at the National Hospital of Pediatrics. Educational Review, 94-97. 